\title{
Photothermal nanoblade for large cargo delivery into mammalian cells
}

\author{
Ting-Hsiang $\mathbf{W u}^{1}$, Tara Teslaa ${ }^{2}$, Sheraz Kalim ${ }^{2}$, Christopher T. French ${ }^{3}$, Shahriar \\ Maghadam $^{3}$, Randolph Wall ${ }^{3,4,5}$, Jeffery F. Miller ${ }^{3,5,6}$, Owen N. Witte $3,4,5,6,7,8$, Michael A. \\ Teitell $2,4,5,6,{ }^{,}, \dagger$, and Pei-Yu Chiou ${ }^{6,9,{ }^{*}, \dagger}$ \\ ${ }^{1}$ Department of Electrical Engineering, University of California, Los Angeles (UCLA), 420 \\ Westwood Plaza, 43-147, Los Angeles, CA 90095 \\ ${ }^{2}$ Department of Pathology and Laboratory Medicine, UCLA, 675 Charles E. Young Dr. South, \\ MRL 4-762, Los Angeles, CA 90095
}

${ }^{3}$ Department of Microbiology, Immunology and Molecular Genetics, UCLA, 615 Charles E. Young Drive South, Los Angeles, CA 90095

${ }^{4}$ Broad Center of Regenerative Medicine and Stem Cell Research, UCLA

${ }^{5}$ Molecular Biology Institute, UCLA, 675 Charles E. Young Dr. South, MRL 5-748, Los Angeles, CA 90095

${ }^{6}$ California NanoSystems Institute, UCLA, 675 Charles E. Young Dr. South, MRL 5-748, Los Angeles, CA 90095

${ }^{7}$ Molecular and Medical Pharmacology, UCLA, 675 Charles E. Young Dr. South, MRL 5-748, Los Angeles, CA 90095

${ }^{8}$ Howard Hughes Medical Institute, UCLA, 420 Westwood Plaza, 37-138, Los Angeles, CA 90095

${ }^{9}$ Department of Mechanical and Aerospace Engineering, UCLA, 420 Westwood Plaza, 37-138, Los Angeles, CA 90095

\section{Abstract \\ It is difficult to achieve controlled cutting of elastic, mechanically fragile, and rapidly resealing mammalian cell membranes. Here, we report a photothermal nanoblade that utilizes a metallic nanostructure to harvest short laser pulse energy and convert it into a highly localized explosive vapor bubble, which rapidly punctures a lightly-contacting cell membrane via high-speed fluidic flows and induced transient shear stress. The cavitation bubble pattern is controlled by the metallic structure configuration and laser pulse duration and energy. Integrating the metallic nanostructure with a micropipette, the nanoblade generates a micron-sized membrane access port for delivering highly concentrated cargo $\left(5 \times 10^{8}\right.$ live bacteria/ml) with high efficiency $(46 \%)$ and cell viability (>90\%) into mammalian cells. Additional biologic and inanimate cargo over 3 -orders of magnitude in size including DNA, RNA, $200 \mathrm{~nm}$ polystyrene beads to $2 \mu \mathrm{m}$ bacteria have also been delivered into multiple mammalian cell types. Overall, the photothermal nanoblade is a new approach for delivering difficult to transfer cargo into mammalian cells.}

*Correspondence: Michael A. Teitell; mteitell@ucla.edu; 675 Charles E. Young Dr. South, MRL 4-762, Los Angeles, CA 90095; TEL: (310) 206-6754; FAX: (310) 267-0382.. "Pei-Yu Chiou; pychiou@ seas.ucla.edu; 420 Westwood Plaza, 37-138, Los Angeles, CA 90095; TEL: (310) 825-8620; FAX: (310) 206-4830..

${ }^{\dagger}$ Co-contributing authors

SUPPORTING INFORMATION AVAILABLE. Additional information as noted in text. This material is available free of charge via the Internet at http://pubs.acs.org. 


\section{INTRODUCTION}

Transferring cargo into mammalian cells over a wide range of sizes, including proteins, DNA, RNA, chromosomes, nuclei, and inanimate particles, such as quantum dots, surfaceenhanced Raman scattering (SERS) particles, and microbeads is highly desirable in many fields of biology. Delivery methods, such as endocytosis, can entrap cargo in an endosome, where the low $\mathrm{pH}$ microenvironment and lytic enzymes often lead to cargo degradation. ${ }^{1}$ Viral and chemical delivery methods package the cargo inside a virus or form chemical complexes that enhance uptake. ${ }^{2,3}$ However, toxicity, cell-type specific uptake, and more importantly limited cargo packing capacity impose a significant constraint on cargo size and transferable cell types. ${ }^{1}$ Physical transfer methods include electroporation ${ }^{4}$ and sonoporation $^{5}$, which produce randomly distributed nanoscale pores, and optoporation ${ }^{6-8}$, which generates pores on the cell membrane at the laser focal point. Through these pores, small cargo is delivered into cells by thermal diffusion or by an electric field. Delivery of large cargo with these methods has low efficiency due to the slow speed of cargo diffusion and decreasing cell viability with increasing pore size. ${ }^{9}$ Microcapillary injection ${ }^{10,11}$ uses a sharp glass tip to mechanically penetrate a cell membrane for delivery. However, mechanical trauma from membrane penetration limits the typical pipette tip to $0.5 \mu \mathrm{m}$ in diameter in order to maintain cell viability. ${ }^{11,12}$ Cargo larger than the pipette tip cannot be injected due to pipette clogging and cargo shearing. Electroinjection, which combines electroporation with microcapillary injection, has demonstrated small molecule delivery, such as RNA and plasmid DNA, into live cells ${ }^{13}, 14$ and bacteria delivery into artificial lipid vesicles ${ }^{15}$ by weakening the contacting cell membrane with an electric field, followed by gentle mechanical penetration into the cell. However, methods for high efficiency delivery of micron-sized cargo into live mammalian cells have yet to be achieved. Alternatively, a simple lipid assisted microinjection (SLAM) technique ${ }^{16}$ incorporates synthetic lipid molecules at the tip of a glass microcapillary. Contact of the SLAM micropipette with a cell membrane allowed the lipid molecules to fuse with the cell membrane to form a continuous and temporary pathway for cargo delivery. This method avoids the zig-zag stabbing motion of the micropipette tip through the cell membrane. However, the lipohilic interactions with cargo and cell membrane could produce unwanted biological effects in the cell as well as with the delivery cargo, limiting this method to specific cell types and cargo contents. One of the major technical barriers is the lack of an ability to open large access ports in cell membranes with minimal damage to mechanically fragile, elastic, and three-dimensional cell membranes.

Collective electron oscillations on metallic nanostructures, known as surface plasmons, have intriguing optical properties and have been utilized to demonstrate novel optical applications including optical cloaking, ${ }^{17}$ superlensing, ${ }^{18}$ near-field imaging, ${ }^{19}$ and SERS detection. ${ }^{20}$ By controlling the three-dimensional configuration of such structures, specific resonance frequencies and optical absorption properties can be designed. ${ }^{21}$ The kinetic energy of oscillating electrons driven by applied electromagnetic fields is converted into lattice heat in picoseconds, ${ }^{22}$ which heats up the surrounding medium through thermal conduction. Such metallic nanostructure-guided photothermal effects have been shown to guide nanowire growth, ${ }^{23}$ actuate micro- and nanoscale fluids, ${ }^{24,}{ }^{25}$ provide photothermal cancer therapy, ${ }^{26,27}$ and trigger drug delivery. ${ }^{28,}{ }^{29}$ An interesting phenomenon occurs when a metallic nanostructure is immersed in aqueous media and heated rapidly with a short laser pulse. A substantial temperature rise is realized in the nanostructure and in the thin surrounding liquid layer over the laser pulse duration. Upon surpassing a threshold energy that superheats the liquid medium, part of the absorbed optical energy is converted into mechanical work through inducing explosive cavitation bubbles that generate localized and high speed fluid flows. ${ }^{25}, 30$ It has been demonstrated that gold nanospheres adhered to a mammalian cell membrane and exposed to nanosecond laser pulses generates randomly 
distributed nanoscale cavitation bubbles and transient membrane pores for small molecule delivery by diffusion, or can cause membrane rupture and cell death if the induced cavitation bubbles are large. $27,31,32$

Here, we developed a photothermal nanoblade that is a metallic nanostructure integrated with a microcapillary pipette (Figure 1). The photothermal nanoblade harvests optical pulse energy to trigger spatially patterned, temporally synchronized cavitation bubbles that generate high-speed, localized fluidic flows. If a soft material or fragile structure, such as a cell membrane, is in contact with the photothermal nanoblade, the ultrafast and localized flow is able to puncture the membrane near the contact area with little mechanical perturbation to the rest of the structure. Membrane cutting is produced by the strong transient mechanical shear stress from the laser-induced cavitation bubble. ${ }^{33-35}$ A delivery portal in the cell membrane is thereby generated without advancing the attached micropipette into the cell. During cutting, the blade is in gentle contact with the membrane, eliminating the need for strong mechanical support underneath the membrane. This new device allows intracellular delivery of variably sized objects, from biomolecules to bacteria, into soft mammalian somatic cells with high efficiency and cell viability.

To demonstrate the photothermal nanoblade, a $100 \mathrm{~nm}$ thick titanium (Ti) thin film was deposited onto the tip of a glass microcapillary pipette with a $2 \mu \mathrm{m}$ tip diameter (Fig. 2A,B). The Ti coated micropipette is mounted on a motorized micromanipulator arm on an inverted microscope stage. With the micropipette tip positioned in light contact with a cell membrane, a $6 \mathrm{~ns} \mathrm{Nd}$-YAG laser pulse at $532 \mathrm{~nm}$ wavelength illuminated a $260 \mu \mathrm{m}$-wide field through the objective lens. Pulsed laser exposure rapidly heats the Ti and adjacent thin water layer to induce a localized vapor bubble explosion along the ring-shaped Ti thin film that cuts the contacting cell membrane. The process, from laser pulsing, Ti heating, cavitation bubble expansion and collapse, takes only a few hundred nanoseconds. Pressurecontrolled delivery of fluid and cargo inside the micropipette is synchronized with laser pulsing and membrane cutting.

\section{MATERIALS AND METHODS}

\section{Device Fabrication and Experimental Setup}

Titanium (Ti)-coated micropipettes were fabricated by heating and pulling (P-97, Sutter Instrument) a $1 \mathrm{~mm}$ diameter borosilicate glass capillary tube, followed by Ti thin film deposition onto the tapered ends using a magnetron sputter deposition system. The Ti coating thickness and the micropipette tip diameter were quantified using a scanning electron microscope. The laser pulse system was a Q-switched, frequency-doubled Nd-YAG laser (Minilite I, Continuum) operated at $532 \mathrm{~nm}$ wavelength and $6 \mathrm{~ns}$ pulsewidth. The laser beam was split by a polarizing beam splitter (Figure S-1), with one arm sent into the fluorescence port of an inverted microscope (AxioObserver, Zeiss) and then through the objective lens $(40 \times, 0.6 \mathrm{NA})$, to generate a $260-\mu$-wide laser spot on the sample plane. The optimized laser fluence used for cargo delivery was $180 \mathrm{~mJ} / \mathrm{cm}^{2}$ (Figure S-2). An electrical switch was built to synchronize the excitation laser pulse with the liquid injection system (FemtoJet, Eppendorf). A time-resolved imaging system to characterize the cavitation bubble dynamics was constructed using an intensified CCD camera (PI-MAX2, Princeton Instruments) with exposure times as short as $500 \mathrm{ps}$. A programmable delay between receiving the laser triggering signal and the camera shutter opening was set by the camera control unit. After the polarizing beam splitter, the other arm of the laser beam was sent through a fluorescent dye cell. The excited fluorescence pulse (wavelength centered $\sim 698$ $\mathrm{nm}$ ) was coupled into a multimode fiber and then sent through the microscope condenser to illuminate the sample in synchronization with the camera shutter. A nanosecond time delay 
between the captured bubble image and the sample excitation laser pulse was controlled by the length of the optical fiber delay line.

\section{Numerical Calculations of Intensity Pattern on the Ti-Coated Micropipette}

The 3D finite difference time domain (FDTD) method was used to simulate the electromagnetic intensity pattern (FullWAVE, RSoft Design Group). The simulation domain was constructed with a water medium region $\left(n_{\text {water }}=1.34\right)$ and a glass micropipette $\left(n_{\text {glass }}\right.$ $=1.46)$ with a $100-\mathrm{nm} \mathrm{Ti}\left(n_{\mathrm{Ti}}=1.86+2.56 i^{36}\right)$ thin film coated on the tip and the outer sidewall. The entire domain was surrounded by perfectly matched boundary layers to mimic an infinitely extending space. Plane wave excitation was used $(\lambda=532 \mathrm{~nm})$ with the electric field polarized along y and the wavevector $k$ making a 30-degree angle with respect to the pipette tip. Time-averaged intensity profiles in $\mathrm{Ti},\left|E_{\text {ave }}\right|^{2}$, were obtained by averaging the normalized electric energy density over one electromagnetic wave oscillation.

\section{Determining the Optimal Laser Fluence of the Photothermal Nanoblade for Membrane Cutting}

Criteria for optimal laser fluence, membrane opening, and maintaining high cell viability were sought. Propidium iodide (PI) dye was added to the cell culture media $(10 \mathrm{mg} / \mathrm{ml})$ before laser pulsing. The micropipette was brought into contact with the cell membrane and illuminated with a laser pulse at the specified fluence level. The treated cell was checked immediately after laser pulsing to verify the uptake of PI. Cell viability was determined separately in a similar fashion with PI added 90 min after laser pulsing, followed by visual growth detection over time.

\section{Cell Viability Evaluation}

Cell viability was determined by annexin $\mathrm{V}$ and propidium iodide (PI) cell staining $90 \mathrm{~min}$ following photothermal nanoblade cutting. To accurately track injected cells, cells were seeded onto a chemically patterned glass coverslip substrate. ${ }^{37}$ Circular areas (diameter $\sim 200 \mu \mathrm{m}$ ) were defined on the substrate to confine cell adhesion and growth within these regions (Figure S-3). For each experiment, every cell within the same circular pattern $(\sim 60$ cells in one pattern) was subjected to the same laser pulsing and cargo delivery conditions. To exclude the viability effects of culturing cells on a patterned substrate, the percentage of viable cells in a treated pattern was further normalized by the percentage of viable cells in a neighboring untreated pattern on the same glass substrate. Post-delivery viability was determined by the average of 3 independent experiments.

\section{Biomolecule, Carboxylate Bead, and Bacterial Delivery with Immunofluorescence Imaging}

GFP-expressing RNA was diluted in $1 \times$ PBS, pH 7.4, and injected into IMR90 primary human lung fibroblasts. DsRed-encoding lentiviral DNA was incubated with cationic, 100 $\mathrm{nm}$ green polystyrene beads to allow DNA adsorption on the spherical surface. The beads were then suspended in $1 \times$ PBS, pH 7.4, and injected into human embryonic stem (hES) cells. hES cells were dissociated and cultured using ROCK $^{38}$ inhibitor on top of a thin layer of matrigel (BD Biosciences). DsRed expression was verified $24 \mathrm{hr}$ post-injection. $200 \mathrm{~nm}$ green carboxylate-modified polystyrene beads were suspended in $1 \times \mathrm{PBS}, \mathrm{pH} 7.4,(0.1 \%$ solid by volume) and injected into HEK293T cells. Fluorescent $B$. thailandensis bacteria were suspended in $1 \times \mathrm{PBS}$, pH 7.4 (concentration $10^{8}-10^{9}$ per ml) and injected into HeLa cells. Cells were cultured in chambered microscope slides (LabTek, Nunc) using Dulbecco's modified Eagle's medium (DMEM) without penicillin and streptomycin. Immediately after the injection, cells were washed 3 times with PBS and incubated for $2 \mathrm{hr}$ in fresh medium containing $1000 \mathrm{mg} / \mathrm{ml}$ kanamycin to kill extracellular bacteria. The growth medium was then replaced with DMEM containing $5 \mathrm{mg} / \mathrm{ml}$ ceftazidime to suppress extracellular 
bacterial growth, and incubated for an additional $16-24 \mathrm{hr}$ at $37^{\circ} \mathrm{C}$ in $5 \% \mathrm{CO} 2$. At $16-24 \mathrm{hr}$ post-injection, cells were fixed with $4 \%$ paraformaldehyde and stained with Alexa-Fluorlabeled phalloidin to visualize the actin cytoskeleton (Invitrogen). Cells were then visualized using a Leica SP2 AOBS laser scanning confocal microscope setup.

\section{Bacterial Strains and Growth Conditions}

Burkholderia thailandensis and mutant derivates were cultured in L-medium. Chloramphenicol $(25 \mu \mathrm{g} / \mathrm{mL})$ or tetracycline $(20 \mu \mathrm{g} / \mathrm{mL})$ were added as required.

\section{Bacterial Invasion Efficiency Assays}

B. thailandensis E264 was grown in L-broth to an optical density $\left(\mathrm{OD}_{600}\right)$ of $1.0\left(4 \times 10^{8}\right.$ $\mathrm{CFU} / \mathrm{mL}$ ). $1 \times 10^{5} \mathrm{HeLa}$ cells grown in 12-well plates were infected with bacteria at a multiplicity of infection (MOI) of 10:1 for $2 \mathrm{hr}$ at $37^{\circ} \mathrm{C}$. The infected cells were then washed with PBS and incubated with fresh medium containing $400 \mu \mathrm{g} / \mathrm{mL}$ kanamycin for $15 \mathrm{~min}$ to kill extracellular bacteria, followed by lysis with $1 \%$ Triton X-100 in PBS. Serial dilutions of the infected HeLa cell lysates were spread on L-agar, and the numbers of intracellular bacteria were determined by assays for CFU.

\section{RESULS AND DISCUSSION}

\section{Simulation of Optical Intensity Patterns on the Photothermal Nanoblade}

The cavitation bubble pattern is controlled by the thin film composition and configuration, as well as laser excitation parameters including wavelength, pulse duration, and energy. Figure $2 \mathrm{c}$ shows the calculated intensity patterns on a laser-excited, Ti-coated micropipette using 3D finite difference time domain (FDTD) simulations. The Ti-coated micropipette is illuminated at an angle of 30 degrees with respect to the tip. Plasmon-enhanced optical absorption $\left(\alpha\left|E_{\text {ave }}\right|^{2}\right)$ is non-uniform across $2 \mu \mathrm{m}$ wide Ti ring for linearly polarized light (Figure 2d). High intensity areas are concentrated on the edges of the rings along the wave polarization direction. The temperature distribution in the Ti ring is governed not only by the heat generated in these high intensity areas, but also by heat diffusion to the cooler metal regions and surrounding medium during laser pulsing. In the Ti film on the micropipette, the estimated heat diffusion length $(\sim \sqrt{D \tau})$ is $230 \mathrm{~nm}$ in $6 \mathrm{~ns}$. This results in a smoother temperature profile along the entire ring-shaped pipette tip. Consequently, thermal energy conducting away from the Ti film heats the adjacent thin water layer to above the critical temperature, ${ }^{25}$ generating a vapor nanobubble on the ring-shaped micropipette tip (Figure 3a).

\section{Cavitation Bubble Induced Membrane Cutting and Corresponding Cell Viability}

For micron-sized cargo delivery into live mammalian cells, a transient membrane portal must accommodate the cargo size. Moreover, the damage zone must also be contained to allow cell repair and maintain viability. Figure 3 a shows cavitation bubbles at the tip of a tilted Ti-coated micropipette 70 nanoseconds after laser pulse irradiation. A dramatic reduction in the bubble size was observed when the tip was in contact with the cell membrane as this interaction impedes bubble expansion. In this case the bubble grew to a maximum radius of $400 \mathrm{~nm}$ away from the rim of the tip in $70 \mathrm{~ns}$ and collapsed completely within $200 \mathrm{~ns}$ after the excitation laser pulse (Figure 3a,b). The blade tip never enters the cell so intracellular structural integrity is preserved, which helps foster rapid, reparative pore resealing, as evidenced by sustained cell viability (Figure 3c). Cell viability was determined by annexin $\mathrm{V}$ and propidium iodide (PI) exclusion staining $90 \mathrm{~min}$ following laser pulsing. Under these conditions, $>90 \%$ cell viability was obtained with laser pulsing and bubble explosion alone (at an optimal fluence of $180 \mathrm{~mJ} / \mathrm{cm}^{2}$, Figure S-2), or when coupled with 
buffer injection into HeLa or HEK293T cells. Monitoring photothermal nanoblade treated cells over $24 \mathrm{hr}$ showed that cells stayed viable and continued to grow and divide as usual (Figure S-3).

\section{Biomolecules and Bacteria Delivery by the Photothermal Nanoblade}

We tested the delivered cargo size range using the photothermal nanoblade on various cell types. GFP-expressing RNA was efficiently delivered into lipofectamine-resistant IMR90 primary human lung fibroblasts and a DsRed-containing lentivirus coated onto $100 \mathrm{~nm}$ green fluorescent polystyrene beads was successfully expressed in ROCK $^{38}$ inhibitor dispersed human embryonic stem cells following injection. Fluorescent beads of $200 \mathrm{~nm}$ in diameter were delivered without clogging, as were micron-sized bacteria (Figure 4). We further evaluated an intracellular bacterium as the largest and most fragile cargo delivered by this approach (Fig. 5). Burkholderia thailandensis ${ }^{39}$ is a rod-shaped bacteria measuring $\sim 0.7 \times 2 \mu \mathrm{m}$. To determine injection efficiency, GFP-labeled bacteria were suspended in buffer at a concentration of $\sim 5 \times 10^{8}$ per ml, 2 orders of magnitude higher than conventional microinjection. ${ }^{40}$ High cargo concentration is critical in achieving high delivery efficiency since the liquid volume delivered into a cell is limited to $\sim 1 \mathrm{pl}$. Without a high concentration, the frequency of ejecting 1 bacterium per injection is low. In our experiment, upon laser pulsing and cell membrane opening, $1-5 \mathrm{pl}$ of the bacterial solution was ejected out of the pipette, corresponding to an average of $\sim 1$ bacteria per injection. Not all the ejected solution was delivered into the cell since the pipette tip was in light contact with the cell membrane, and the bore of the pipette was not in a perfect seal with the membrane after cutting. Under this condition, we obtained an average delivery efficiency of $46 \%$ from multiple independent experiments (Table S-1). We further evaluated the natural bacterial invasion efficiency in HeLa cells by incubating cells with B. thailandensis for $2 \mathrm{hr}$. The delivery efficiency by photothermal injection is 2 orders of magnitude higher than the natural HeLa cell infectivity of $B$. thailandensis of $0.8 \%$. Importantly, bacteria remained viable and were protected from destruction during bubble cycles within the glass pipette and from shearing during injection by the large bore tip opening as verified by bacteria multiplication and actin polymerization ${ }^{41}$ in the injected cells $24 \mathrm{~h}$ after transfer (Figure 5c).

\section{Reliability Evalution of the Photothermal Nanoblade}

For robust operation, the metallic thin film must withstand high temperature and intense pressure from the shockwave and high-speed flows generated by cavitation bubbles. Ti was chosen as the coating material for its higher melting temperature and strong adhesion to the glass substrate compared with other inert metals such as gold. ${ }^{42}$ It has been shown in our experiments that a gold-coated micropipette failed after a few laser pulses due to thin film damage. We verified that a Ti-coated micropipette remained functional through at least 50 laser pulsing and bubble explosion cycles. (Figure S-4).

\section{CONCLUSIONS}

The photothermal nanoblade holds promise for delivering currently untransferable large cargo into mammalian cells, such as chromosomes, organelles, and intracellular pathogens that are beyond the size constraints of contemporary delivery approaches. An additional advantage of the photothermal nanoblade is its ease of use. Since membrane cutting is controlled by the laser pulse energy and the Ti coating configuration, the user simply positions the micropipette tip in gentle contact with the cell membrane to perform delivery. By contrast, for conventional glass microcapillary microinjection, delivery efficiency and cell viability is strongly influenced by the manner in which the glass needle enters the cell (e.g. speed, force, angle). As a result, the conventional method requires substantial training and experience for a user to become proficient. There is also less chance to break the fragile 
micropipette tip using the photothermal nanoblade since it does not require a rapid "zig-zag" motion for the micropipette to penetrate and leave the cell. The photothermal nanoblade does not operate under any specific surface plasmon resonance modes in current demonstration. Further optimization of the metallic nanostructure to match the excitation laser wavelength could reduce the threshold laser energy for exciting cavitation bubbles.

\section{Supplementary Material}

Refer to Web version on PubMed Central for supplementary material.

\section{Acknowledgments}

The authors thank Dr. Kayvan Niazi and Dr. Shahrooz Rabizadeh (California NanoSystems Institute and Abraxis BioScience) for helpful discussions and support. We gratefully thank Isla P. Garraway, Rita U. Lukacs, Eric H. Gschweng, Xinqiang Huang, and Jennifer Anderson for exceptional technical support, and the CNSI Advanced Light Microscopy and Spectroscopy Facility at UCLA, which is supported by an NIH-NCRR shared resources grant (CJX1-443835-WS-29646) and NSF Major Research Instrumentation grant (CHE-0722519). This project is supported by the NSF (CBET 0853500 and ECCS 0901154), a UC Discovery/Abraxis BioScience Biotechnology Award (\#178517), the NIH Roadmap for Medical Research Nanomedicine Initiative (PN2EY018228), the Broad Center of Regenerative Medicine and Stem Cell Research at UCLA, the Prostate Cancer Foundation Challenge Award, and the Pacific Southwest Regional Center of Excellence in Biodefense and Emerging Infectious Diseases (U54 AI065359).

\section{REFERENCES}

(1). Luo D, Saltzman WM. Nat Biotechnol. 2000; 18:33-37. [PubMed: 10625387]

(2). Naldini L, Blomer U, Gallay P, Ory D, Mulligan R, Gage FH, Verma IM, D T. Science. 1996; 272:263-267. [PubMed: 8602510]

(3). Felgner PL, Gadek TR, Holm M, Roman R, Chan HW, Wenz M, Northrop JP, Ringold GM, Danielsen M. Proc. Natl. Acad. Sci. USA. 1987; 84:7413-7417. [PubMed: 2823261]

(4). Chu G, Hayakawa H, Berg P. Nucleic Acids Res. 1987; 15:1311-1326. [PubMed: 3029703]

(5). Mitragotri S. Nat Rev Drug Discov. 2005; 4:255-260. [PubMed: 15738980]

(6). Tirlapur UK, König K. Nature. 2002; 418:290-291. [PubMed: 12124612]

(7). Vogel A, Noack J, Hőttman G, Paltauf G. Appl. Phys. B. 2005; 81:1015-1047.

(8). Clark IB, Hanania EG, Stevens J, Gallina M, Fieck A, Brandes R, Palsson BO, Koller MR. J. Biomed. Opt. 2006; 11:014034. [PubMed: 16526911]

(9). Stevenson D, Agate B, Tsampoula X, Fischer P, Brown CTA, Sibbett W, Riches A, Gunn-Moore F, Dholakia K. Opt. Express. 2006; 14:7125-7133. [PubMed: 19529083]

(10). King, R. Gene delivery to mammalian cells by microinjection. Methods in Molecular Biology 245: Gene Delivery to Mammalian Cells 1. Humana Press Inc.; Totowa, NJ: 2004.

(11). Zhang, Y. Nature Protocols. http://www.natureprotocols.com/2007/11/02/microinjection_technique_and_p.php

(12). Han S-W, Nakamura C, Kotobuki N, Obataya I, Ohgushi H, Nagamune T, Miyake J. Nanomed. Nanotechnol. Biol. Med. 2008; 4:215-225.

(13). Boudes M, Pieraut S, Valmier J, Carroll P, Scamps F. J. Neurosci. Meth. 2008; 170:204-211.

(14). Kitamura K, Judkewitz B, Kano M, Denk W, Häusser M. Nat. Methods. 2008; 5:61-67. [PubMed: 18157136]

(15). Hurtig J, Orwar O. Soft Matter. 2008; 4:1515-1520.

(16). Laffafian I, Hallett MB. Biophys. J. 1998; 75:2558-2563. [PubMed: 9788951]

(17). Kildishev AV, Shalaev VM. Nature Photonics. 2007; 1:224-227.

(18). Fang N, Lee H, Sun C, Zhang X. Science. 2005; 308:534-537. [PubMed: 15845849]

(19). Betzig E, Trautman JK. Science. 1992; 257:189-195. [PubMed: 17794749]

(20). Nie S, Emory SR. Science. 1997; 21:1102-1106. [PubMed: 9027306]

(21). Prodan E, Radloff C, Halas NJ, Nordlander P. Science. 2003; 302:419-422. [PubMed: 14564001] 
(22). Link S, El-Sayed MA. J. Phys. Chem. B. 1999; 103:8410-8426.

(23). Cao L, Barsic DN, Guichard AR, Brongersma ML. Nano Lett. 2007; 7:3523-3527. [PubMed: 17963415]

(24). Liu GL, Kim J, Lu Y, Lee LP. Nat. Mater. 2005; 5:27-32. [PubMed: 16362056]

(25). Kotaidis V, Dahmen C, von Plessen G, Springer F, Plech A. J. Chem. Phys. 2006; 124:184702. [PubMed: 16709126]

(26). Jain PK, El-Sayed IH, El-Sayed MA. Nano Today. 2007; 2:18-29.

(27). Lapotko DO, Lukianova E, Oraevsky AA. Laser Surg. Med. 2006; 38:631-642.

(28). Skirtach AG, Dejugnat C, Braun D, Susha AS, Rogach AL, Parak WJ, Mohwald H, Sukhorukov GB. Nano Lett. 2005; 5:1371-1377. [PubMed: 16178241]

(29). Lee SE, Liu GL, Kim F, Lee LP. Nano Lett. 2009; 9:562-570. [PubMed: 19128006]

(30). Lukianova-Hleb E, Hu Y, Latterini L, Tarpani L, Lee S, Drezek RA, Hafner JH, Lapotko DO. ACS Nano. 2010; 4:2109-2123. [PubMed: 20307085]

(31). Pitsillides CM, Joe EK, Wei XB, Anderson RR, Lin CP. Biophys. J. 2003; 84:4023-4032. [PubMed: 12770906]

(32). Wu T-H, Kalim S, Callahan C, Teitell MA, Chiou P-Y. Opt. Express. 2010; 18:938-946. [PubMed: 20173916]

(33). Marmottant P, Hilgenfeldt S. Nature. 2003; 423:153-156. [PubMed: 12736680]

(34). Lokhandwalla M, Sturtevant B. Phys. Med. Biol. 2001; 46:413-437. [PubMed: 11229723]

(35). Hellman A, Rau KR, Yoon HH, Venugopalan V. J. Biophoton. 2008; 1:24-35.

(36). Lynch, DW.; Hunter, WR. Introduction to the data for several metals. Handbook of optical constants of solids III. Academic Press; San Diego, CA: 1998.

(37). Peterbauer T, Heitz J, Olbrich M, Hering S. Lab Chip. 2006; 6:857-863. [PubMed: 16804589]

(38). Watanabe K, Ueno M, Kamiya D, Nishiyama A, Matsumura M, Wataya T, Takahashi JB, Nishikawa S, Nishikawa S-I, Muguruma K, Sasai Y. Nat. Biotechnol. 2007; 25:681-686. [PubMed: 17529971]

(39). Wiersinga WJ, van der Poll T, White NJ, Day NP, Peacock SJ. Nat. Rev. Microbiol. 2006; 4:272-282. [PubMed: 16541135]

(40). Goetz M, Bubert A, Wang G, Chico-Calero I, Vazquez-Boland J, Beck M, Slaghuis J, Szalay AA, Goebel W. Proc. Natl. Acad. Sci. USA. 2001; 98:12221-12226. [PubMed: 11572936]

(41). Stevens JM, Ulrich RL, Taylor LA, Wood MW, DeShazer D, Stevens MP, Galyov EE. J. Bacteriol. 2005; 187:7857-7862. [PubMed: 16267310]

(42). Benjamin P, Weaver C. Proc. Roy. Soc. London A. 1961; 261:516-531. 


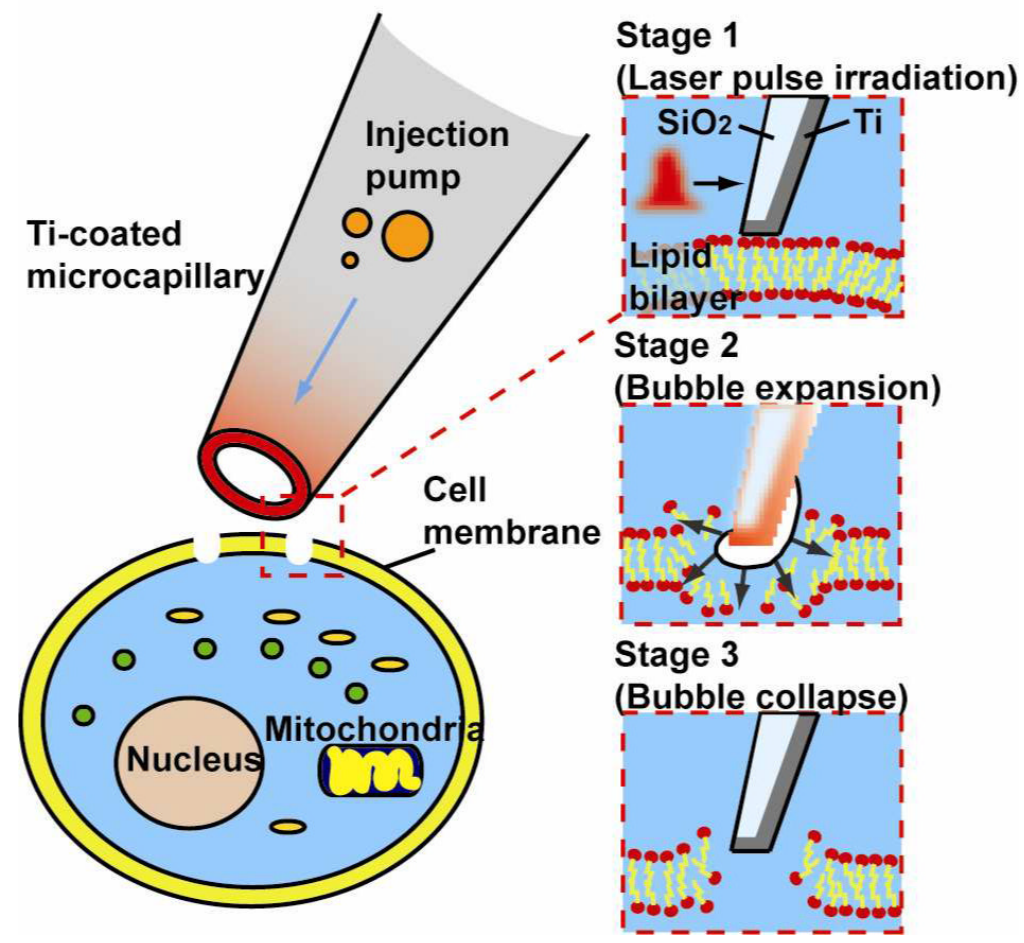

Figure 1.

Ultrafast membrane cutting mechanism using a photothermal nanoblade for cargo delivery into live mammalian cells. A Ti thin film coats the outside of a glass micropipette. Upon excitation by a nanosecond laser pulse, the Ti heats rapidly, along with a thin surrounding aqueous layer through heat conduction. An explosive vapor nanobubble that expands and collapses in $<1 \mu$ s locally cuts the contacting cell membrane in synchronization with pressure-driven delivery of the microcapillary contents. 

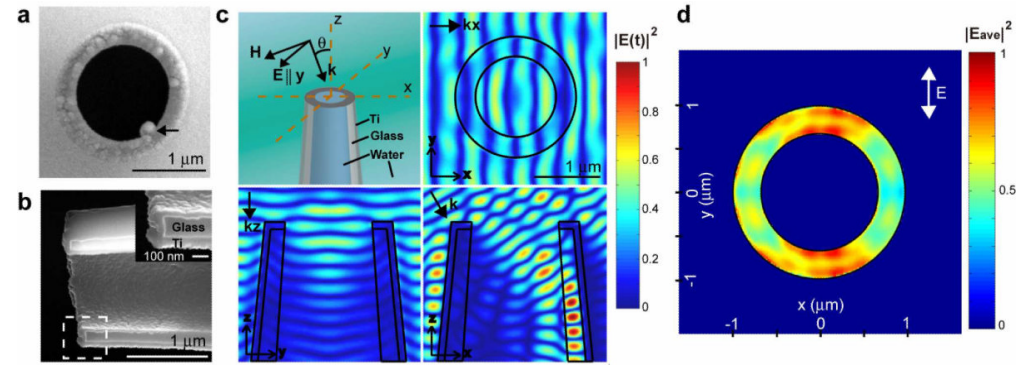

Figure 2.

Structure of a Ti-coated micropipette and the calculated intensity pattern from laser excitation. (a,b) Scanning electron microscope images of a pulled, Ti-coated micropipette. Inner diameter $=1.38 \pm 0.1 \mu \mathrm{m}$ (mean \pm s.d. $)$. Outer diameter $=1.88 \pm 0.1 \mu \mathrm{m}$. Thickness of Ti thin film $=102 \pm 8 \mathrm{~nm}$ (The arrow points to edge of the glass filament running inside the micropipette). (c) Normalized intensity profiles at the tip of the micropipette under laser excitation $\left(n_{\mathrm{Ti}}=1.86+2.56 i,{ }^{36} n_{\text {glass }}=1.46, n_{\mathrm{water}}=1.34, \lambda=532 \mathrm{~nm}, \theta=30^{\circ}\right)$. (d) Timeaveraged optical absorption profiles $\left(\propto \mid E_{\text {ave }}{ }^{2}\right)$ in the Ti ring at the micropipette tip. 

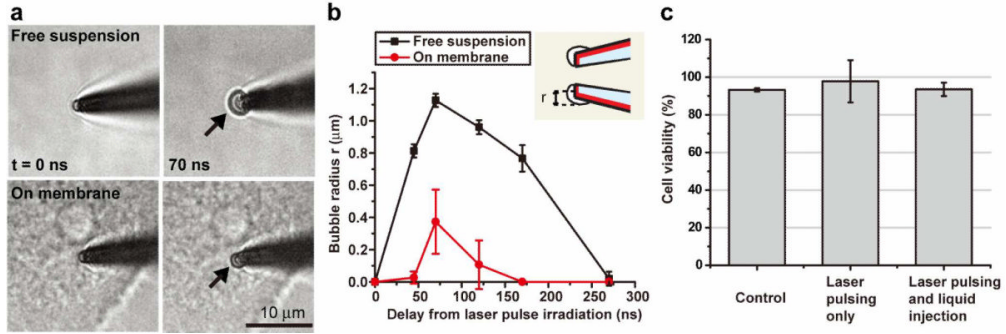

Figure 3.

Ultrafast membrane cutting by the photothermal nanoblade and cell viability evaluation. (a) A nanobubble with maximum radius extending to $0.4 \mu \mathrm{m}$ from the rim of the pipette tip when in contact with the cell membrane. Energy transfer to the contacting membrane reduces the size of nanobubble formation and locally cuts the plasma membrane. (b) Fast expansion and collapse dynamics of a vapor nanobubble within $270 \mathrm{~ns}$ in free suspension and $170 \mathrm{~ns}$ in contact with a HeLa cell membrane. (c) Cell viability post photothermal delivery. The control experiment was performed using a glass-only micropipette in contact with the cell (no piercing through the membrane) and illuminating with a laser pulse at the same fluence $\left(180 \mathrm{~mJ} / \mathrm{cm}^{2}\right)$. Cell viability is $>90 \%$ when cells were subjected to laser pulsing and membrane opening alone $(98 \pm 11 \%$ (mean \pm s.d.)) and in experiments where cells were subjected to laser pulsing and liquid injection $(94 \pm 4 \%)$. 


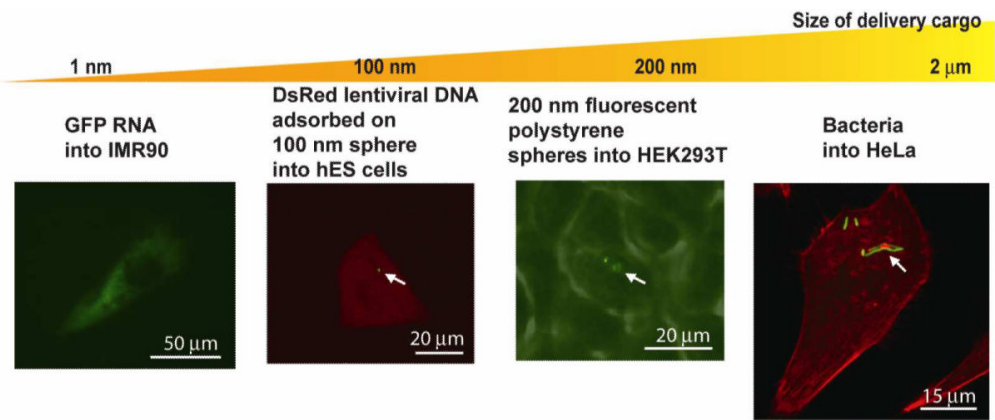

Figure 4.

Wide range of deliverable cargo sizes by the photothermal nanoblade. GFP-expressing RNA was delivered into lipofectamine-resistant IMR90 primary human lung fibroblasts. DsRedcontaining lentivirus coated onto a $100 \mathrm{~nm}$ green fluorescent bead was expressed in ROCK inhibitor dispersed human embryonic stem cells following transfer. Fluorescent beads of 200 $\mathrm{nm}$ in diameter were delivered into HEK293T cells without clogging. B. thailandensis bacterial transfer into HeLa cells was achieved with high efficiency and high cell viability. 
a

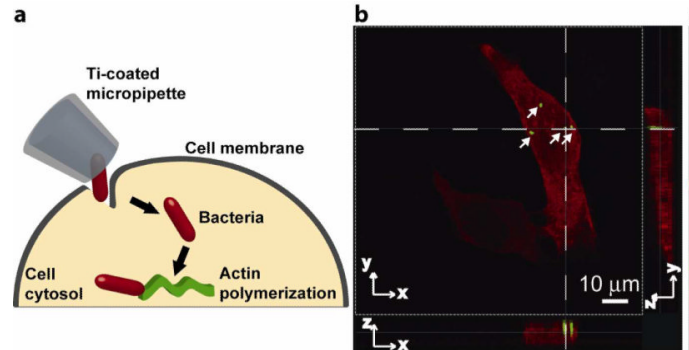

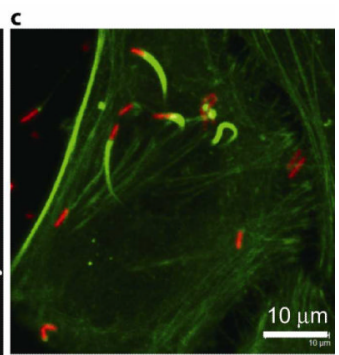

Figure 5.

High efficiency bacterial delivery into HeLa cells by the plasmonic phothermal nanoblade. (a) Pathway of bacterial uptake following transfer. ${ }^{39}$ (b) GFP-labeled Burkholderia thailandensis was transferred into a HeLa cell (average efficiency $=46 \pm 33 \%$ (mean \pm s.d.)) along with red-fluorescent dextran-tetramethylrhodamine. Confocal z-axis scanning showing multiple bacteria inside a red-fluorescent cell. (c) Multiplication and actin polymerization of transferred mCherry-labeled B. thailandensis in HeLa cells. 